\title{
Совершенствование законодательного регулирования в сфере приграничной торговли*
}

Павлов П.В.**

Наименее исследованным режимом внешнеторговой деятельности является приграничная торговля. В статье рассматриваются вопросы приграничного сотрудничества России с сопредельными государствами, определяется статус приграничных территорий, анализируется европейский опыт приграничного сотрудничества, проводится анализ основных нормативных документов в области торговой деятельности приграничных регионов, выявляются основные институциональные проблемы приграничных торговых отношений и предлагаются подходы к их решению путем совершенствования существующего законодательства.

Ключевые слова: внешнеторговая деятельность; приграничное сотрудничество; приграничная торговля; льготные меры регулирования.

Эволюция международных отношений в начале XXI века позволила России по-новому взглянуть на общую ситуацию, переосмыслить приоритеты российской внешней политики с учетом возросшей роли страны в международных делах, повышения ее ответственности за происходящее в мире и открывшихся в связи с этим возможностей участвовать в формировании международной обстановки. Укрепление международных позиций России, а также решение задач, связанных с установлением равноправных, взаимовыгодных, партнерских отношений со всеми странами, успешное продвижение ее внешнеэкономических интересов, обеспечение политического, экономического, информационного и культурного влияния за рубежом требуют использования всех имеющихся в распоряжении государства финансово-экономических рычагов и адекватного ресурсного обеспечения внешней политики Российской Федерации, важной частью которой является внешнеторговая политика. Главная задача внешнеторговой политики любого государства - обеспечение благоприятных условий для эффективной

\footnotetext{
* Публикуется в порядке дискуссии

** Павлов Павел Владимирович - д.ю.н., доцент кафедры экономики и финансов Таганрогского института управления и экономики. pavel_pavlov@beriev.com.
} 
деятельности отечественного бизнеса в сфере внешней торговли, а тем самым и для эффективного развития национальной экономики в целом.

Наименее исследованным особым режимом внешнеторговой деятельности является приграничная торговля. Сама идея приграничной торговли призвана содействовать социально-экономическому развитию соответствующих регионов и предполагает установление для них особого льготного налогового, таможенного, валютного режимов. Двойственность правового регулирования приграничной торговли заключается в том, что, с одной стороны, эта деятельность осуществляется на территории государства и подчиняется его национальному праву, а с другой - является разновидностью внешнеэкономической деятельности с присутствием иностранного элемента, что отражается на выборе механизмов государственного управления этой деятельностью.

В современных условиях проблемы приграничного сотрудничества исключительно актуальны для Российской Федерации, которая имеет огромную по протяженности (более 4200 км) границу с Китаем - важнейшим экономическим и политическим ее партнером. Кроме того, на северо-западе РФ граничит с Норвегией, Финляндией, Прибалтийскими государствами и Польшей. Более половины российских регионов имеют общие границы с иностранными государствами или выход во внешние моря. При этом большинство из периферийных регионов приобрели такой статус совсем недавно ${ }^{1}$.

Совершенствование процесса регулирования приграничной торговли как особого режима внешнеторговой деятельности способно выступить в качестве конституционно-правовой гарантии реализации принципа федерализма, защиты гражданско-правовых интересов хозяйствующих субъектов, а также государственной поддержки стратегически значимых территорий.

Международный подход решения институциональных проблем приграничных отношений предполагает признание государствами того факта, что приграничные территориальные сообщества одного государства в пределах его законодательной системы наделены компетенцией непосредственно регулировать отношения и заключать законные сделки с приграничными сообществами, расположенными на территории другого государства. Одной из причин для появления прямых приграничных отношений между регионами является то, что государства,

${ }^{1}$ Бильчак В.С. Приграничная экономика: Монография. Калининград: Изд-во КГУ, 2001. C. $121-122$. 
особенно в приграничных зонах, не могут оперативно и удовлетворительно решать задачи, которые входят в сферы их ответственности. Вторая причина появления институциональных приграничных отношений - транснациональные и интеграционные изменения в приграничном регионе. В перспективе окончательным решением становится расширение сферы полномочий и ответственности приграничных сообществ и их институтов в соответствии с внутренним законодательством. Ярким примером этого процесса может послужить опыт приграничного сотрудничества европейских государств.

Основополагающими документами для формирования правовой базы приграничного сотрудничества в Европе можно считать многостороннее Генеральное соглашение о тарифах и торговле (ГАТТ), заключенное в 1947 году, и Европейскую рамочную конвенцию по приграничному сотрудничеству территориальных сообществ и властей ${ }^{2}$.

В Европейской рамочной конвенции под приграничнылм сотрудничеством понимаются любые согласованные действия, направленные на укрепление и поощрение добрососедских отношений между территориальными сообществами или властями, находящимися под юрисдикцией двух или более договаривающихся сторон, и заключение любых соглашений и договоренностей, необходимых для достижения этих целей. Приграничное сотрудничество осуществляется в рамках полномочий территориальных сообществ или властей, определяемых внутренним правом каждой из сторон (п. 1 ст. 2 Конвенции).

Во многих научных источниках и законодательных актах размеры приграничного региона определяются двумя параметрами: граница как физическое понятие и приграничный регион как территория с существующими двусторонними экономическими и социальными связями. Гранииа - это прежде всего физическое понятие, которое обычно обозначается указателями, определяющими территорию государства ${ }^{3}$. Она указывает сферу действия национального суверенитета, составляя тем самым ключевой элемент национальной территории или любой другой национальной системы, включающей различные подсистемы, например национальная система образования, национальная экономика,

2 Ратифицирована в России Федеральным законом от 22.07.2002 №91-Ф3 «О ратификации Европейской рамочной конвенции о приграничном сотрудничестве территориальных сообществ и властей» // СЗ РФ. 29.07.2002. № 30. Ст. 3008. Вступила в силу для России 05.01.2003.

3 Закон РФ от 1 апреля 1993 г. № 4730-1 «О Государственной границе Российской Федерации» // Ведомости СНД и ВС РФ. 1993. № 17. Ст. 594. 
национальная валюта, национальная безопасность, правосудие и т.д. ГАТТ рассматривает приграничную торговлю в качестве преференциального исключения из режима наибольшего благоприятствования для сопредельных стран на территории около 15 км от границы.

На основе европейского опыта и нормативных документов ГАТТ и Европейской рамочной конвенции формировалась правовая база приграничного сотрудничества сначала Советского Союза, а затем и России. В нашей стране приграничная торговля появилась и получила свое развитие как компромисс между централизацией внешней торговли и стремлением региональных органов власти мобилизовать местные ресурсы, обменять их путем бартерных операций в сопредельных странах в целях решения некоторых задач, в основном по снабжению своего населения товарами потребительского назначения. В частности, в Соглашение 1989 года между Правительством СССР и Правительством Турецкой Республики о приграничной и прибрежной торговле определено, что данная торговля будет осуществляться на сбалансированной основе, с тем чтобы стоимость товаров, поставляемых из одной страны в течение определенного периода, соответствовала стоимости товаров, поставляемых из другой страны ${ }^{4}$.

В России исследования по приграничному сотрудничеству начались в основном после распада СССР в 1991 году. Ученые и специалисты справедливо отмечали резкое снижение роли государства в регулировании приграничных процессов, ослабление внешнеэкономических связей с бывшими союзными республиками и отсутствие реальной таможенной политики в данный период, что отрицательно сказывалось на экономике приграничных регионов. В результате, если в приграничных регионах, богатых сырьевыми ресурсами, наблюдалась относительная стабилизация в социально-экономическом развитии, то развитые в прошлом приграничные регионы России со значительным промышленным и научным потенциалом, высокой плотностью населения переживали глубокий кризис и спад производства. В них очень резко возросли различия по уровню жизни с соседними регионами, что вызывало социальную напряженность и отражалось на межнациональных отношениях. Сказывалось также отсутствие соглашений о приграничном сотрудничестве между Россией и сопредельными государствами, что

\footnotetext{
${ }^{4}$ Соглашение между Правительством Союза Советских Социалистических Республик и Правительством Турецкой Республики о приграничной и прибрежной торговле. Москва, 6 июля 1989 г.
} 
не позволяло периферийным регионам более слаженно решать совместные проблемы с приграничными регионами соседних государств 5 .

Для устранения этих негативных явлений в рамках отношений в области приграничного сотрудничества между правительствами отдельных государств - членов СНГ (Республика Беларусь, Республика Казахстан, Кыргызская Республика, Российская Федерация и Республика Таджикистан) 26 февраля 1999 г. было подписано Соглашение об основных принципах приграничного сотрудничества государств участников договора об углублении интеграции в экономической и гуманитарной областях ${ }^{6}$. В нем под межрегиональным и приграничнымм сотрудничеством государств - участников СНГ понимаются согласованные действия органов государственной власти, органов власти административно-территориальных единиц государств-участников СНГ, органов местного самоуправления, юридических лиц, общественных организаций, совершаемые в рамках действующего законодательства государств - участников СНГ, направленные на укрепление всесторонних отношений сопредельных государств в решении вопросов устойчивого развития регионов и приграничных территорий, повышения благосостояния населения приграничных территорий, обеспечения безопасности жизни граждан, охраны окружающей среды и взаимопомощи в чрезвычайных ситуациях, упрочения дружбы и добрососедства государств - участников СНГ. Целью данного соглашения провозглашено содействие процессам расширения и развития интеграции между приграничными регионами, установление взаимовыгодных связей. В статье 7 данного соглашения говорится о том, что в целях привлечения инвестиций, углубления экономической интеграции и ускоренного развития приграничных регионов стороны совместно изучат экономические и правовые возможности создания на их территориях различных типов свободных экономических зон (СЭЗ) и зон приграничной торговли и примут согласованные решения. В рамках этого решения 15 сентября 2004 года Совет Глав Правительств СНГ утвердил Концепцию межрегионального и приграничного сотрудничества государств участников $\mathrm{CH}^{7}$. Концепция определила основные задачи, принци-

5 Бильчак В.С. Приграничная экономика: Монография. Калининград: Изд-во КГУ, 2001. C. 5-9.

${ }^{6}$ Ратифицировано Федеральным законом РФ от 06.12.2000 г. № 140-Ф3 // СЗ РФ. 2000. № 50. Ст. 4863.

7 Решение о Концепции межрегионального и приграничного сотрудничества государств - участников Содружества Независимых Государств. Астана, 15 сентября 2004 г. 
пы и направления реализации политики государств - участников СНГ по развитию межрегионального и приграничного сотрудничества.

Существующая нормативная база, определяющая условия деятельности в России территорий с особым режимом внешнеэкономической деятельности, к настоящему времени состоит из нескольких законодательных актов. В первую очередь это Федеральный закон РФ от 8 декабря 2003 г. № 164-Ф3 «Об основах государственного регулирования внешнеторговой деятельности», который впервые определил понятие особых режимов осуществления отдельных видов внешнеторговой деятельности - приграничную торговлю и особые экономические зоны ${ }^{8}$. Но если деятельность особых экономических зон с 2005 года регулируется отдельным Федеральным законом РФ от 22 июля 2005 г. № 116-Ф3 «Об особых экономических зонах в РФ» ${ }^{9}$, то для приграничной торговли до настоящего времени отдельного нормативного акта принято не было.

Российское законодательство пошло по пути унификации законодательства о приграничной торговле с форматом ГАТТ. Поэтому норма статьи 41 «Приграничная торговля» Федерального закона РФ «Об основах государственного регулирования внешнеторговой деятельности» во многом схожа с нормой, закрепленной в статье XXIV ГАТT. Данная статья содержит правила, по которым «Договаривающиеся Стороны признают желательным расширение свободы торговли путем развития посредством добровольных соглашений более тесного объединения экономик стран - участниц таких соглашений. Они также признают, что целью таможенного союза или зоны свободной торговли должно быть облегчение торговли между составляющими их территориями, а не создание барьеров в торговле между другими Договаривающимися Сторонами и данными территориями» ${ }^{10}$. В части 3 ранее упомянутой статьи 41 определено, что порядок осуществления приграничной торговли и соответствующие приграничные территории, на которых устанавливаются особые режимы осуществления внешнеторговой деятельности, определяются Правительством Российской Федерации в соответствии с международными договорами Российс-

${ }^{8}$ C3 РФ. 2003. №50. СТ. 4850.

${ }^{9}$ С3 РФ. 2005 . №30 (ч. 2). Ст. 3127.

10 Козырин А.Н. и др. Постатейный комментарий к Федеральному закону «Об основах государственного регулирования внешнеторговой деятельности». М.: Городец, 2005. 
кой Федерации с сопредельными иностранными государствами и федеральными законами.

Эти нормативные акты предусматривают понятие приграничной торговли как предоставление особого благоприятного режима внешнеторговой деятельности в отношении внешней торговли товарами и услугами, осуществляемой исключительно для удовлетворения местных потребностей в товарах и услугах, произведенных в пределах соответствующих приграничных территорий и предназначенных для потребления физическими лицами, имеющими постоянное место жительства на этих территориях, и юридическими лицами, имеющции место нахождения на этих территориях. Территория, на которой осуществляется приграничное сотрудничество, может определяться в международных договорах Российской Федерации, соглашениях субъектов Российской Федерации с иностранными партнерами, заключаемых в порядке, определяемом законодательством Российской Федерации.

Участниками приграничного сотрудничества в Российской Федерации в пределах своей компетенции могут являться федеральные органы исполнительной власти, органы исполнительной власти субъектов Российской Федерации и органы местного самоуправления, а также юридические и физические лица в соответствии с законодательством Российской Федерации. Регулирование приграничной торговли относится к предметам совместного ведения Российской Федерации и субъекта Федерации. При этом различные аспекты внешнеторговой деятельности субъектов приграничной торговли регулируются такими общеприменимыми в области международной торговли федеральными законами, как «О валютном регулировании и валютном контроле», «О международном коммерческом арбитраже», «О таможенном тарифе». Кроме того, для них применим и ряд законов общеэкономического характера, таких как Таможенный кодекс РФ, Гражданский кодекс РФ, Налоговый кодекс РФ и др.

Современная приграничная торговля является одним из важнейших аспектов приграничных связей России. Это положение нашло правовое закрепление в Концепции приграничного сотрудничества в Российской Федерации ${ }^{11}$. В ней для развития приграничного сотрудничества первым среди рекомендуемых направлений деятельности названо сотрудничество в приграничной торговле, которое осуществляется меж-

11 Утверждена распоряжением Правительства Российской Федерации от 9 февраля 2001 года № 196-p. 
ду российскими юридическими и физическими лицами, имеющими постоянное место нахождения (место жительства) на приграничной территории Российской Федерации, и иностранными лицами, имеющими постоянное место нахождения (место жительства) на сопредельной приграничной территории, исключительно для удовлетворения местных нужд в товарах, производимых на соответствующих приграничных территориях.

В Концепции приграничного сотрудничества сказано, что приграничная территория Российской Федерации включает в себя пограничную зону, российскую часть вод пограничных рек, озер и иных водоемов, внутренних морских вод и территориального моря Российской Федерации, где установлены пограничный режим, пункты пропуска через Государственную границу Российской Федерации, а также территории административных районов и городов, санаторно-курортных зон, особо охраняемых природных территорий, объектов и других территорий, прилегающих к Государственной границе Российской Федерации, пограничной зоне, берегам пограничных рек, озер и иных водоемов, побережью моря или пунктам пропуска. Таким образом, понятие «приграничная территория» включает несколько составляющих, каждая из которых имеет важное значения для определения границ применения особого режима внешнеторговой деятельности.

Основным законодательным актом, определяющим правовой режим водной территории, является Федеральный закон от 31 июля 1998 г. № 155-Ф3 «О внутренних морских водах, территориальном море и прилежащей зоне»12. В ст. 1 данного закона внутренние морские воды определяются как воды, расположенные в сторону берега от исходных линий, от которых отмеряется ширина территориального моря Российской Федерации. Территориальное море - это примыкающий к сухопутной территории или к внутренним морским водам морской пояс шириной 12 морских миль, отмеряемый от исходных линий. Определение территориального моря применяется также ко всем островам Российской Федерации.

В соответствии с ч. 2 ст. 67 Конституции ${ }^{13}$ Российская Федерация обладает суверенными правами и осуществляет юрисдикцию также на континентальном шельфе и в исключительной экономической зоне Российской Федерации в порядке, определяемом федеральным законом

12 СЗ РФ. 1998. № 31. Ст. 3833.

13 РГ. 1993. 25 дек. 
и нормами международного права. Указанные территории обладают так называемым смешанным режимом. Хотя они не входят в состав государственной территории прибрежного государства, такое государство осуществляет в их пределах определенные суверенные права и несет обязанности, установленные внутренним законодательством и международным правом.

Установлению правового режима континентального шельфа посвящен Федеральный закон от 30 ноября 1995 г. № 187-Ф3 «О континентальном шельфе Российской Федерации» ${ }^{14}$. Внешняя граница континентального шельфа находится на расстоянии 200 морских миль от исходных линий, от которых отмеряется ширина территориального моря. Права Российской Федерации на континентальный шельф не затрагивают правовой статус покрывающих его вод и воздушного пространства над этими водами.

Коммерческое использование исключительной экономической зоны также регулируется международным правом и законодательством прибрежного государства. В современном международном праве под исключительной экономической зоной прибрежного государства понимается район моря, включающий водную толщу, морское дно и его недра, находящийся за пределами территориального моря прибрежного государства, прилегающий к нему и имеющий особый правовой режим. Сказанное применимо также ко всем островам прибрежного государства.

В настоящее время в Российской Федерации действует Федеральный закон от 17 декабря 1998г. № 191-Ф3 «Об исключительной экономической зоне Российской Федерации» ${ }^{15}$. Наряду с этим в отношении исключительной экономической зоны действуют общепринятые принципы международного права и нормы ратифицированных Россией международных договоров. Внешняя граница исключительной экономической зоны России находится на расстоянии 200 морских миль от исходных линий, от которых отмеряется ширина территориального моря. В отношении исключительной экономической зоны прибрежное государство располагает такими же суверенными правами, как и в отношении континентального шельфа. Они включают права на разведку, разработку и сохранение живых и неживых природных ресурсов в водах, на морском дне и в его недрах. Помимо этого они включа-

14 СЗ РФ. 1995. № 49. Ст. 4694.

${ }^{15}$ СЗ РФ. 1998. № 51. Ст. 6273. 
ют управление природными ресурсами, а также право экономической разведки и разработки зоны.

Для России еще предстоит найти свой путь развития приграничного сотрудничества. В этом важном деле следует взвешенно опираться на мировой опыт. При этом нужно использовать все позитивное, что уже наработано странами, но не просто копировать эти механизмы, а адаптировать их к российским географическим, экономическим, политическим особенностям, историческим традициям.

Анализ существующего законодательства в области приграничного сотрудничества выявил ряд существующих проблем, мешающих осуществлению полноценного процесса межрегиональной интеграции и развитию международных торговых отношений с соседними странами. Это вызывает необходимость корректировки и совершенствования существующего законодательства.

Bo-nepвыx, должно быть нормативно закреплено само понятие «приграничная территория» как объект установления особого экономического режима. Это можно сделать, приняв отдельный федеральный закон «О приграничной торговле» или внеся соответствующие изменения в существующий закон «Об основах государственного регулирования внешнеторговой деятельности». При этом нельзя всю территорию субъектов Российской Федерации, имеющих выход к государственной границе, относить к приграничным территориям. К ним, в частности, можно относить только административные районы и муниципальные образования, которые имеют непосредственный выход к государственной границе.

Bo-вmopblx, применение льготных мер, способных создать предпосылки для ускоренного социально-экономического развития приграничных территорий, не должно наносить ущерб доходной части федерального бюджета и экономической безопасности страны. Должна существовать утвержденная на федеральном уровне методика расчета интегральной эффективности (социальной, налоговой, бюджетной и т.п.) предоставления данных льгот. Должны быть предусмотрены сроки, критерии и жесткие процедуры контроля эффективности и результативности вводимых мер, формы ответственности и санкции за нарушение установленных законом норм и правил. Данные документы можно утвердить в виде совместных нормативно-правовых актов Министерства промышленности и торговли России, Министерства финансов России, Федеральной таможенной службы России. 
$B$-третьих, серьезные проблемы связаны и с объемом предоставляемых льгот. Если они будут чрезмерными, то в неравном положении окажутся регионы, не участвующие в приграничной торговле. Возникнет ситуация, когда число регионов, занятых в данной торговле, начнет расти. Все новые территории, не являющиеся, по сути, ни приграничными, ни прибрежными, захотят участвовать в указанной торговле в целях получения льгот. В итоге начнут страдать общенациональные интересы. Проконтролировать этот процесс в сложившихся условиях вполне реально, установив жесткие границы и критерии применения льгот в зависимости от территории их использования.

$B$-четвертыхx, объектом предоставления таможенных и налоговых льгот должны стать товары, не только произведенные, но и переработанные на приграничной территории. При разработке критерия оnределения происхождения товаров с приграничной территории прообразом его могут стать критерии достаточной переработки товаров в Калининградской ${ }^{16}$ или Магаданской особых экономических зонах ${ }^{17}$. Данный критерий должен предусматривать необходимость предоставления органам местного самоуправления приграничных территорий права самостоятельно устанавливать величину добавленной стоимости при переработке таких товаров для отнесения их к категории «льготных», но в пределах норм, установленных на федеральном уровне.

$B$-nяmblx, так как при осуществлении приграничной торговли изъятие из общего порядка таможенно-тарифного и нетарифного регулирования касается исключительно товаров и лиц, произведенных (переработанных) и проживающих на приграничной территории, нельзя допустить, чтобы в приграничную торговлю стали вовлекаться и экспортироваться в обход действующего порядка товары, произведенные за пределами регионов, имеющих право заниматься упомянутой торговлей. Необходимо разработать механизмы, препятствующие распространению льготного режима на другие субъекты внутри страны, а также методы контроля за этим процессом.

$B$-шестыхx, для развития приграничной торговли государство может использовать не только экономические формы поддержки, но и такие,

16 Федеральный закон РФ от 10 января 2006 г. № 16-Ф3 «Об особой экономической зоне в Калининградской области и о внесении изменений в некоторые законодательные акты Российской Федерации» // СЗ РФ. 2003. № 3. Ст. 280.

${ }^{17}$ Федеральный закон РФ от 31 мая 1999 г. № 104-Ф3 «Об особой экономической зоне в Магаданской области» // РГ. 1999. 7 июня. 
как установление упрощенного (безвизового) режима перехода границы для лиц, проживающих на приграничных территориях; обеспечение занятости населения с предоставлением уведомительного (а не разрешительного) права работы на приграничной территории сопредельного государства; право на беспрепятственный ввоз/вывоз валютной выручки за реализованные товары на приграничной территории или полученной заработной платы за работу на территории сопредельного государства. Проработку данных вопросов необходимо поручить Министерству иностранных дел России, Федеральной миграционной службе РФ, Федеральной службе безопасности РФ, Министерству финансов РФ.

$B$-седbмых, целью регулирования внешнеэкономических отношений в форме развития особого режима приграничной торговли должно быть не предоставление льгот отдельным регионам или субъектам торговли, а целостное стимулирование развития тех территорий, которые по объективным причинам не могут функционировать в режиме саморазвития (например, новые российские приграничные регионы, у которых существовали налаженные в течение многих лет экономические, культурные, социальные отношения с сопредельными государствами - бывшими республиками Советского Союза); активизация социальной мобильности населения; создание условий для возникновения государственно значимых потенциальных «точек роста», аналогичных таким специальным территориальным образованиям, как особые экономические зоны ${ }^{18}$.

Принятие данных мер позволит наряду с конкретной помощью приграничным территориям решить важные задачи общефедерального значения: компенсировать дополнительную нагрузку на инфраструктуру приграничных территорий, обусловленную наличием государственной границы; предоставить возможность приграничным территориям использовать особенности своего положения и осуществлять торговые виды деятельности с большей отдачей для экономики страны, развить сеть пограничных переходов до современного уровня оснащенности и сервиса с широкой гаммой оказываемых услуг, что в конечном итоге

${ }^{18}$ Павлов П.В. Особые экономические зоны как институциональные инструменты включения России в глобализирующееся мировое хозяйство: Монография / Под науч. ред. проф. А.Ю. Архипова. Ростов н/Д: Изд-во РГУ, 2006. 
минимизирует издержки обращения внешнеторговых операций на всей территории России ${ }^{19}$.

\section{Библиографический список}

Бильчак В.С. Приграничная экономика: Монография. Калининград: Изд-во КГУ, 2001.

Козырин А.Н. и др. Постатейный комментарий к Федеральному закону «Об основах государственного регулирования внешнеторговой деятельности». М.: Городец, 2005.

Кущенко В.В. Особые режимы внешнеэкономической деятельности: право и практика: Учебно-практическое пособие. М.: ВГНА МНС РФ, Книжный мир, 2004.

Павлов П.В. Особые экономические зоны как институциональные инструменты включения России в глобализирующееся мировое хозяйство: Монография / Под науч. ред. проф. А.Ю. Архипова. Ростов н/Д: Изд-во РГУ, 2006.

\section{Improvement of Legislative Control for Boarder Trade (Summary)}

Pavel V. Pavlov*

The border trade is the least investigated treatment of foreign trade activity. In this Article author determines the questions of boarder cooperation of Russia with appointed states, defines status of boarder territories, analyzes European experience of boarder cooperation, makes an analyzes of the basic regulatory documents within the province of trade activity in boarder regions, discovers the main institutional problems of boarder trade relations and suggests the ways to solve these problems by improvement of existing legislation.

Keywords: foreign trade activity; boarder cooperation; boarder trade; preferential control ways.

${ }_{19}^{19}$ Кущенко В.В. Особые режимы внешнеэкономической деятельности: право и практика: Учебно-практическое пособие. М.: ВГНА МНС РФ, Книжный мир, 2004. С. 87-89. * Pavel V. Pavlov - Ph.D. in Law, assistant professor; senior lecturer at the Chair of Economy and Finance of Taganrog management and economics Institute.pavel_pavlov@beriev.com. 